\title{
TRABALHO E PERSPECTIVAS SOB A COMPREENSÃO DOS CATADORES DE RECICLÁVEIS DE FORTALEZA-CE
}

Thaís Silva de Araújo - thaisdearaujo518@gmail.com , Instituto Federal de Educação, Ciência e Tecnologia do Ceará - IFCE (Campus Fortaleza).

Ana Paula Silva Sales - anapaulassales@hotmail.com , Instituto Federal de Educação, Ciência e Tecnologia do Ceará - IFCE (Campus Fortaleza).

Gemmelle Oliveira Santos - gemmelle@ifce.edu.br, Instituto Federal de Educação, Ciência e Tecnologia do Ceará - IFCE (Campus Fortaleza).

\section{RESUMO}

Esse trabalho é parte de um projeto de extensão aprovado no Edital 001/2016 PROEXT/IFCE e está vinculado ao Departamento da Área de Química e Meio Ambiente do Campus Fortaleza, e objetivou conhecer suas condições de trabalho, bem como as perspectivas, dos catadores de materiais recicláveis autônomos de Fortaleza-Ceará. Uma análise mais geral permite perceber que as atividades laborais como catador tiveram início na infância e se estenderam até vida adulta, como forma de geração de renda individual e familiar. Por outro lado, alguns entrevistados afirmaram trabalhar como catador de recicláveis por causa do desemprego e por ser um serviço que não exige "chefia". Os dados obtidos apontam que $80 \%$ dos entrevistados coletam material em pelo menos 5 dias da semana para obter o maior volume possível de material. Curiosamente, 24\% dos entrevistados não conseguem perceber nenhuma dificuldade nesse tipo de trabalho. Existem ainda aqueles que afirmam como dificuldade: encontrar material com qualidade (12\%), separar os recicláveis entre os resíduos misturados $(12 \%)$, vender os materiais a preços tão 
baixos (6\%), sofrer discriminação e o preconceito $(6 \%)$, utilizar carrinhos inadequados (4\%) e trabalhar mesmo com limitações físicas $(2 \%)$.

Palavras-Chave: Resíduos sólidos, Catadores de materiais recicláveis, Trabalho.

\section{INTRODUÇÃO}

A demanda industrial por matérias primas e os elevados índices de desemprego tem resultado também no aumento progressivo do número de indivíduos que vivem da coleta seletiva e da reciclagem no Brasil.

Estimativas do Instituto de Pesquisa Econômica Aplicada - IPEA (2013) aponta que no Brasil existem aproximadamente 600 mil catadores de materiais recicláveis, sendo que $30 \%$ estão localizados na região Nordeste.

Os catadores de resíduos, que ora atuam individualmente ora coletivamente em unidades de triagem, associações ou cooperativas, participam de um crescente mercado informal de trabalho e, em muitos casos, realizam suas atividades sob precárias condições laborais, como bem destacou Feitosa (2014).

Esses trabalhadores desempenham papel fundamental na implementação da Política Nacional de Resíduos Sólidos (PNRS) já que atuam nas atividades da coleta seletiva, triagem, classificação, processamento e comercialização dos resíduos reutilizáveis e recicláveis, contribuindo de forma significativa para a cadeia produtiva da reciclagem (BRASIL, 2016).

Em Fortaleza (Ceará), a catação de materiais recicláveis e reutilizáveis acontece desde 1956 (SANTOS e RIGOTTO, 2008) e até a presente data pouco se conhece sobre suas condições de trabalho.

Esse trabalho é parte de um projeto de extensão aprovado no Edital 001/2016 PROEXT/IFCE e está vinculado ao Departamento da Área de Química e Meio Ambiente do Campus Fortaleza.

\section{METODOLOGIA}


Esta pesquisa classificou-se como aplicada, pois voltou-se à aquisição de conhecimentos com vistas à aplicação numa situação específica (GIL, 2002); exploratória, ou seja, buscou ter maior familiaridade com o problema (LAKATOS; MARCONI, 2003); do tipo estudo de campo, pois foi realizada no local onde acontece o fato/fenômeno/processo (GIL, 2002); quanto à abordagem, foi quantitativa; quanto ao método, usou o indutivo, pois partiu de dados particulares, devidamente constatados, para concluir uma verdade geral.

A primeira etapa da pesquisa envolveu a revisão de literatura sobre o tema principal com o objetivo de aumentar a compreensão sobre o assunto. A segunda etapa abrangeu a elaboração de um formulário, considerando a literatura, com perguntas abertas e fechadas que buscou conhecer mais detalhes sobre as condições de trabalho dos catadores. O trabalho de campo permitiu entrevistar 50 catadores autônomos encontrados aleatoriamente entre os meses de agosto e setembro de 2016 na cidade de Fortaleza-CE. A terceira etapa consistiu no tratamento das informações e dados e análise quantitativa mediante nova visita à literatura.

\section{RESULTADOS E DISCUSSÃO}

Uma análise mais geral permite perceber que as atividades laborais como catador tiveram início na infância e se estenderam até vida adulta, como forma de geração de renda individual e familiar. Por outro lado, alguns entrevistados afirmaram trabalhar como catador de recicláveis por causa do desemprego e por ser um serviço que não exige "chefia".

Os dados encontrados demonstram que $40 \%$ dos entrevistados trabalham um turno, $34 \%$ dois turnos, $24 \%$ três turnos e $2 \%$ não souberam informar, ratificando os dados da literatura.

O trabalho desenvolvido pelo catador ocorre em péssimas condições, sob exploração financeira e sem direitos sociais e trabalhistas (MONTENEGRO, 2010).

A quantidade de dias dedicados por esses trabalhadores para a catação é outro dado relevante para o melhor entendimento do tema proposto por esse trabalho. Os dados obtidos apontam que $80 \%$ dos entrevistados coletam material em pelo menos 5 dias da semana. 
Uma jornada tão exaustiva se explica pela necessidade de obter o maior volume possível de material podendo assim obter um ganho maior.

Os indivíduos que mais influem nos índices da reciclagem no Brasil são os catadores de resíduos sólidos, pois são responsáveis por coletar quase $90 \%$ de todo o material que é enviado às recicladoras brasileiras (Compromisso Empresarial para a Reciclagem - CEMPRE, 2011).

O serviço prestado pelos catadores de materiais reutilizáveis e recicláveis, profissão já reconhecida pela Classificação Brasileira de Ocupações do Ministério do Trabalho e Emprego, minimiza indiretamente a poluição do solo, água e ar, contribui com a limpeza da cidade, possibilita uma maior vida útil aos aterros sanitários e diretamente gera renda aos envolvidos na cadeia dos materiais.

Entre os 50 catadores entrevistados, 26\% acreditam que o maior risco envolvido com o trabalho que exercem é adquirir alguma doença, sofrer cortes (18\%), violência enquanto dorme na rua (15\%), ser atropelado (13\%) e 7\% responderam outros acidentes. Há ainda uma parte deles (21\%) que não percebe nenhum risco.

Segundo Galon (2015), os catadores de materiais sofrem diversas formas de adoecimento ou desgaste de saúde e, apesar de terem conhecimento sobre os aspectos que causam seu adoecimento, sua prioridade é a busca pela sobrevivência.

A Norma Regulamentadora ${ }^{\circ} 15$, do Ministério do Trabalho e Emprego, considera a atividade do catador como insalubre em grau máximo. Por isso, os catadores representam um grupo que precisa ser atendido pela Política Nacional de Saúde do Trabalhador, já que a mesma contempla pessoas e grupos em situação de maior vulnerabilidade, em atividades de maior risco para a saúde e submetidas a formas nocivas de discriminação (MINISTÉRIO DA SAÚDE, 2012).

No que diz respeito às dificuldades encontradas no trabalho, $18 \%$ dos entrevistados destacam o esforço físico como um dos problemas, pois há excesso de peso e caminhadas extensas, além disso disputam espaço entre os veículos no trânsito da cidade, sofrendo desrespeito dos motoristas. Outro empecilho é a exposição as intempéries (sol e chuva) que possibilitam o surgimento de doenças de pele e até câncer.

O trabalho desenvolvido pelos catadores permite a exposição desses sujeitos a agentes físicos (ruído, poeira, calor e frio), agentes químicos (embalagens contaminadas por 
substâncias tóxicas sólidas, líquidas ou gasosas) e agentes biológicos (bactérias, fungos, vírus e parasitas) - MINISTÉRIO DA SAÚDE (2002).

De acordo com Hoefel et al. (2013) os catadores sabem da periculosidade do ambiente de trabalho e, a maioria, já sofreu algum tipo de acidente. Após um dia de trabalho, os catadores relatam dores musculares, na coluna, cefaleia, resfriados e um extremo cansaço devido à exposição ao sol e esforços físicos (L. DOBRACHINSKI; DOBRACHINSKI, 2016).

O trabalho do catador é insalubre e repleto de riscos de acidentes, o que agrava sua qualidade de vida e condição social. Conforme Cavalcante, Silva e Lima (2014), os riscos de acidentes são aqueles decorrentes do ambiente de trabalho que causam algum tipo de dano, doença ou até mesmo morte do trabalhador. Ainda segundo esses autores, tais riscos são intensificados pelo uso inadequado de ferramentas impróprias e/ou defeituosas, como também pela não utilização de Equipamentos de Proteção Individual - EPI durante as atividades laborais. Esse pensamento é compartilhado por Batista, Lima e Silva (2013).

Entre os entrevistados, $80 \%$ afirmaram não utilizar EPI e 14\% afirmaram utilizar alguns equipamentos (como luvas, botas, chapéu, óculos e/ou protetor solar). Há ainda um grupo ( $6 \%$ dos entrevistados) que afirmou, às vezes, utilizar um saco plástico nas mãos como se fosse uma luva. Como se observa, a maior parte dos catadores entrevistados encontram-se desprotegidos e em péssimas condições laborais.

Todos os entrevistados trabalham diariamente pelas ruas de Fortaleza e utilizam carrinhos (geralmente feitos com carcaça de geladeira) para transportar os materiais que encontram. Curiosamente, $24 \%$ dos entrevistados não conseguem perceber nenhuma dificuldade nesse tipo de trabalho. Existem ainda aqueles que afirmam como dificuldade: encontrar material com qualidade (12\%), separar os recicláveis entre os resíduos misturados (12\%), vender os materiais a preços tão baixos $(6 \%)$, sofrer discriminação e o preconceito (6\%), utilizar carrinhos inadequados (4\%) e trabalhar mesmo com limitações físicas (2\%).

No estudo feito por Abreu (2011), com 50 catadores de Goiás, a maioria dos entrevistados considerou que realiza grande esforço físico no trabalho e $60 \%$ acha que o esforço físico acaba resultando em doenças, sendo que $22 \%$ se queixaram de dor na coluna.

Cavalcante, Silva e Lima (2014) identificaram esforço físico intenso, levantamento e transporte manual de peso, exigência de postura inadequada, jornada de trabalho 
prolongada, além de situações de estresse que são intensificados pelo uso dos carros de catação inadequados.

\section{CONSIDERAÇÕES FINAIS}

- Observou-se que persistem diversas formas de fragilidades nas atividades dos catadores autônomos de materiais recicláveis, entre eles o trabalho penoso, jornadas exaustivas para obter o maior volume possível de materiais, influenciando assim no ganho maior, porém prevalecendo uma renda baixa aos trabalhadores.

- Verificou-se que as condições laborais são extremamente precárias, visto que, permeiam o contato direto com os resíduos, expostos a diversos riscos físicos, químicos, biológicos e acidentais, com relevância dos materiais perfurocortantes sem as devidas medidas de proteção.

- Certificou-se que os entrevistados não conseguem perceber nenhuma dificuldade no seu trabalho, mesmo expostos a diversos riscos laborais.

\section{REFERÊNCIAS}

ABREU, E. $P$ de. Condições de trabalho, saúde e hábitos de vida dos catadores de resíduos sólidos da vila Vale do Sul em Aparecida de Goiânia-GO. 2011. 66 f. Dissertação (Mestrado em Ciências Ambientais e Saúde) - Pós-Graduação em Ciências ambientais e Saúde, Pontifícia Universidade Católica de Goiás, Goiânia, 2011.

BATISTA, R. Coletores de Lixo e Riscos Ocupacionais: estudo de caso no município de São Miguel do Iguaçu. 2012. 48 f. Monografia (Especialização) - Universidade Tecnológica Federal do Paraná, Medianeira, 2012.

BRASIL, Ministério do Meio Ambiente. Catadores de Materiais Recicláveis. Disponível em: $<$ http://www.mma.gov.br/cidades-sustentaveis/residuos-solidos/catadores-de-materiais$\underline{\text { reciclaveis }>\text { Acesso em } 26 \text { de setembro de } 2016 .}$ 
CAVAlCANTE, L. P. S.; SILVA, M. M. P. da; LIMA, V. L. A. de. Análise comparativa de riscos ergonômicos e de acidentes que envolvem catadores de materiais recicláveis organizados e informais. In: CONGRESSO BRASILEIRO DE GESTÃO AMBIENTAL, 5., 2014, Belo Horizonte. Anais... Belo Horizonte: IBEAS, 2014.

COMPROMISSO EMPRESARIAL PARA RECICLAGEM-CEMPRE, 2011. Disponível em: http://www.cempre.org.br/ acessado em: 08 de jan. 2016.

DOBRACHINSKI, L.; DOBRACHINSKI, M. M. M. Condições de vida, trabalho e saúde dos catadores de materiais recicláveis do lixão de um município do Oeste da Bahia. Hígia, Barreiras-BA, v. 1, n. 1, p. 18-45, 2016.

FEITOSA, T.V.N.. Qualidade de Vida no Trabalho em Condições Extremas. 2014. 107 f. Mestrado Acadêmico em Administração - Centro de Estudos Sociais Aplicados, Universidade Estadual do Ceará. Fortaleza, 2014.

GALON, T. Do lixo à mercadoria, do trabalho ao resgate: estudo do processo de trabalho e suas implicações na saúde dos catadores de materiais recicláveis. 2015. 225 f. Tese (Doutorado em Ciências) - Pós-Graduação em Enfermagem Fundamental, Universidade de São Paulo, Ribeirão Preto, 2015.

GIL, A. C. Como elaborar projetos de pesquisa. São Paulo: Atlas, 2010. GONÇALVES, C. V. et al. A vida no lixo: um estudo de caso sobre os catadores de materiais recicláveis no município de Ipameri, GO. Holos, Rio Grande do Norte, v. 2, n. 29, p. 238-250, 2013.

HOEFEL, M. da G. et al. Acidentes de trabalho e condições de vida de catadores de resíduos sólidos recicláveis no lixão do Distrito Federal. Rev. Bras. Epidemiol., São Paulo, v. 16, n. 3, p. 764-785, set. 2013. 
INSTITUTO DE PESQUISA ECONÔMICA APLICADA - IPEA. Situação Social das

Catadoras e dos Catadores de Material Reciclável e Reutilizável. Relatório de Pesquisa: Brasília-DF, 2013.

IPEA - INSTITUTO DE PESQUISA APLICADA ECONÔMICA - Brasília: Ipea, 2013. Pesquisa do Ipea retrata a situação socioeconômica dos catadores de material reciclável.

Disponívele: $<$ http://www.ipea.gov.br/portal/index.php?option=com_content\&view= article\&id=19474\&catid=10\&Itemid=9> Acesso em 24 de setembro de 2016.

IPEA - INSTITUTO DE PESQUISA APLICADA ECONÔMICA - Brasília: Ipea, 2016. Panorama Ipea discute a situação dos catadores no Brasil. Disponível: $<$ http://www.ipea.gov.br/portal/index.php?option=com_content\&view=article\& $\mathrm{id}=27664 \&$ catid=30\&Itemid=9 $>$ Acesso em 24 de setembro de 2016.

MONTENEGRO, D. M. (Re) ligando os fios invisíveis da espoliação: trabalhadores do lixo e a ativação dos limites da precariedade do trabalho. 2010. 164 f. Dissertação (Mestrado em Sociologia) - Pós-Graduação em Sociologia, Universidade Federal do Ceará, Fortaleza, 2010.

SANTOS, G. O.; RIGOTTO, R. M. Possíveis impactos sobre o ambiente e a saúde humana decorrentes dos lixões inativos de Fortaleza (CE). Revista Saúde e Ambiente. Joinville, v. 9, n. 2, p. 55-62, dez. 2008. 